\title{
Fabrication and Investigation of 26NCA Films Exhibiting Tunable Blue Fluorescence Based on LVPVDM
}

\author{
Yufeng Ding, Liangliang Pan, Siqi Li, Huimei He, Dapeng Zhang, Xinyue Hu, \\ Ruoyu Zhang, Yun Wang $\mathbb{D}$, Xiaoyu Zhai $\mathbb{D}$, and Qingyun Meng $\mathbb{D}$ \\ Beijing University of Chemical Technology, Beijing 100029, China \\ Correspondence should be addressed to Yun Wang; wyun@mail.buct.edu.cn, Xiaoyu Zhai; xiaoyuzhai1992@163.com, \\ and Qingyun Meng; mqybuct@163.com
}

Received 11 December 2017; Accepted 27 February 2018; Published 15 April 2018

Academic Editor: Xuping Sun

Copyright (C) 2018 Yufeng Ding et al. This is an open access article distributed under the Creative Commons Attribution License, which permits unrestricted use, distribution, and reproduction in any medium, provided the original work is properly cited.

\begin{abstract}
The development of metallic fluorescent materials, $\pi$-conjugated molecular systems with high-efficiency generation of blue light, and new ways to fabricate metallic/organic luminescent materials plays an important role in the fields of large-scale flat panel displays and soft optical devices. Herein, different fluorescent films have been fabricated by low vacuum physical vapor deposition method (LVPVDM), including single/two-component films. Compared with raw materials, all films show novel fluorescent behaviors, which means potential application in the fields of multicolor luminescence and thickness-optical response sensors. Meanwhile, the speculation is demonstrated in many ways that the maximum emission $\left(\lambda_{\mathrm{em}}{ }^{\max }\right)$ at $406 \mathrm{~nm}$ and $426 \mathrm{~nm}$ of pristine 2,6-naphthalenedicarboxylic acid (26NCA) is caused by the crystal structure, while the shoulder peak at $445 \mathrm{~nm}$ is caused by the self-structure of 26NCA molecule. Significantly, this speculation may afford new insight into the relationship between not only crystal structure and luminescence, but also molecular self-structure and luminescence, which means a new strategy to tune the fluorescent behaviors based on molecular self-structure by LVPVDM. Therefore, this work provides a facile way to fabricate single/multicomponent metallic/organic film materials with tunable blue luminescence properties, which have potential application in the fields of next generation of photofunctional materials.
\end{abstract}

\section{Introduction}

Organic solid-state photoactive chromophores have received increasing attention during the past 20 years due to their unique optical properties and promising optoelectronic applications in the fields of lasers $[1,2]$, sensors [37], and biological imaging [8-10]. Meanwhile, more and more research attention has been paid to molecule-based micro/nanomaterials in chemistry, materials science, and pharmaceutics/medicine [11-14], since micro/nanomaterials exhibit unique properties superior to those of their bulk counterparts $[15,16]$, owing to their surface effect, quantum size effect $[17,18]$, and so on. In addition, inorganic micro/nanomaterials have been most widely investigated from the very beginning of the rise of nanoscience [19]. However, little attention has been focused on the fluorescence of nanoscale metal, especially, tunable fluorescence of lowmolecular-weight materials by fabricating organic/metallic composite/layer films. Significantly, key scientific and technologic problems must be resolved before these photoactive molecular materials can be employed in practical optoelectronic devices, including relatively low crystallinity to low-molecular-weight crystals, and lower melting temperature and poorer mechanical properties to micro/nanoscale organic molecular materials. There are fewer routes for fabricating small organic compounds into nanostructures. The top-down strategy for producing inorganic nanostructures, especially, is difficult to apply to organic materials. Size-dependent optical and electronic properties are not anticipated in organic nanomaterials because, unlike the case of Wannier excitons in inorganic semiconductor and metal crystals, the optoelectronic properties of organic crystals are determined by charge transfer excitons and Frenkel excitons with smaller radius [19-23]. Thus, setting up effective ways to tune and control the photophysical properties of organic materials and metallic materials is a prerequisite for 
developing new generation multicolor luminescent devices, flexible and soft optical devices, and large-scale flat panel display devices [24-30].

Recent developments in solid-state supramolecular chemistry (crystal engineering) have significantly enhanced our understanding on molecular recognition and intermolecular interactions based on low-molecular-weight building blocks [31-34], where bottom-up self-organization of different molecular units offers the opportunity to develop new types of micro/nanostructured crystalline molecular solids. In addition, multicomponent strategies based on molecular recognition and self-assembly have emerged as a new direction for the design and fabrication of molecule-based micro/nanomaterials with tunable composition, crystal structures, solid-state morphologies, and properties. Significantly, this has also shed new light on the structure-performance relationships for molecular solids at the micro/nanometer scale [35-37]. Inorganic nanomaterials have been widely studied by researchers all over the world, including the preparation, shape control, and size-dependent properties. Therefore, the fabrication and investigation of micro/nanostructured film can be achieved by physical or chemical method, including single-component metallic and organic films and multicomponent organic/metallic and organic/organic composite/layer films.

Compared with the development of green/red lightemitting materials, the high-efficiency generation of UV and blue light in molecular systems continues to be a challenge, although UV/blue luminescence has great potential uses in light-emitting diodes for full-color displays and information storage devices [38-40]. 2,6-Naphthalenedicarboxylic acid (26NCA) is a well-known blue fluorescent molecule. In addition, In is mainly used in the production of ITO target materials due to its strong light permeability and electric conductivity. However, little attention has been focused on the tunable fluorescence of micro/nanostructured single/twocomponent metallic/organic fluorescent films, which are expected to be used in large-scale flat panel display [29]. Octafluoronaphthalene (OFN) crystal has one maximum emission $\left(\lambda_{\mathrm{em}}{ }^{\max }\right)$ at $353 \mathrm{~nm}$, which is different from the one of 26NCA; thus 26NCA/OFN layer film is expected to present multicolor luminescence and even be used in soft optical device $[29,41]$.

Up to now, while most studies about the preparation of luminescent materials were focusing on solution process, materials' growth by gaseous phase process had gained little attention, although the latter possessed several advantages, including green environmental protection, shorter growth period, simpler synthetic process, and more accurate control over the thickness of films in comparison with solution process. Moreover, it can solve the problem that low solubility will not be beneficial to the material's growth by solution process, such as 26NCA, and it provides a way to prepare light-emitting film materials which can be utilized in largescale flat panel display and soft optical device [29] by selecting appropriate substrate and photoactive materials. The work, herein, is based on LVPVDM to prepare singlecomponent metallic In film and organic 26NCA film and two-component films of 26NCA/In and 26NCA/OFN and study the fluorescence properties.

\section{Experimental Section}

2.1. Reagents and Materials. 2,6-Naphthalenedicarboxylic acid (purity (GC) $(\mathrm{T})>98.0 \%$ ) was purchased from TCI (Shanghai) Development Co. Ltd. and used without further purification. Octafluoronaphthalene (purity: 96\%) was purchased from Tianjin Heowns Biochem Technologies Co. Ltd. and used without further purification. Microscope slides $(10 \mathrm{~mm} \times 10 \mathrm{~mm} \times 1 \mathrm{~mm})$ were SAIL BRAND. Anhydrous ethanol solution (mass fraction: min. 99.7\%) and acetone (mass fraction: min. 99.5\%) were purchased from Beijing Chemical Works and used without further purification.

\subsection{Preparation of In, 26NCA, 26NCA/In, and 26NCA/OFN} Films. Microscope slides were cleaned by ultrasound for 10 minutes in anhydrous ethanol, acetone, and deionized water, respectively. In, 26NCA, 26NCA/In, and 26NCA/OFN films were prepared by LVPVDM at high temperature (melting point), $157^{\circ} \mathrm{C}, 313^{\circ} \mathrm{C}$, and $87^{\circ} \mathrm{C}$, respectively, while the environmental pressure was 5 pascals and growth time was 1 minute to 20 minutes with a DH2010 Multifunctional Vacuum Experimental Instrument. In and 26NCA films were prepared by heating pristine In and $26 \mathrm{NCA}$, respectively. 26NCA/In layer films were prepared by heating pristine $26 \mathrm{NCA}$ and In successively, which means that 26NCA was heated at first, and then In would be heated. 26NCA/OFN layer films were prepared by heating pristine 26NCA and OFN successively. 26NCA 10 layers film $(750 \mathrm{~nm})$ was prepared by repeating ten times for the preparation of $75 \mathrm{~nm}$ 26NCA film. 26NCA/OFN 10-layer film (1200 nm) was prepared by repeating ten times for the preparation of $60 \mathrm{~nm} / 60 \mathrm{~nm}$ 26NCA/OFN layer film. 26NCA/In layer films especially (26NCA film: $300 \mathrm{~nm}$; In films: $1000 \mathrm{~nm}, 2000 \mathrm{~nm}$, and $3000 \mathrm{~nm}$, resp.) were prepared, where every In film unit was $1000 \mathrm{~nm}$, which meant $2000 \mathrm{~nm}$ and $3000 \mathrm{~nm}$ In films were prepared by repeating two and three times, respectively, for the preparation of $1000 \mathrm{~nm}$ In film in Figure 4(c). $60 \mathrm{~nm} / 1800 \mathrm{~nm}$ 26NCA/OFN film was fabricated, where the film was prepared by heating the mixture including $26 \mathrm{NCA}$ and OFN with suitable stoichiometric ratio in Figure 5(e).

2.3. Characterization. X-ray diffraction (XRD) patterns were recorded using a Bruker D8 Advance X-ray diffractometer under the following conditions: $40 \mathrm{kV}, 40 \mathrm{~mA}, \mathrm{Cu} \mathrm{K} \alpha$ radiation $(0.154184 \mathrm{~nm})$ with a scanning rate of $10^{\circ} / \mathrm{min}$, and a $2 \theta$ angle ranging from $5^{\circ}$ to $31^{\circ}$ for In film and 26NCA films and $60 \mathrm{~nm} / 900 \mathrm{~nm}$ 26NCA/OFN layer film, $1^{\circ}$ to $28^{\circ}$ for $60 \mathrm{~nm} / 600 \mathrm{~nm}$ 26NCA/In layer film and 26NCA/OFN 10 -layer film, and $5^{\circ}$ to $60^{\circ}$ for pristine 26NCA and OFN. Surface morphology was recorded on a Hitachi S-4700 field emission scanning electron microscope (SEM). Solid-state fluorescence spectra were recorded on a Hitachi F-7000 FL Spectrophotometer with $600 \mathrm{~V}$ photomultiplier voltage. The excitation slit and emission slit were both set to be $10.0 \mathrm{~nm}$ with $260 \mathrm{~nm}$ excitation light for In film. The excitation slit and emission slit were both set to be $5.0 \mathrm{~nm}$ with $270 \mathrm{~nm}$ excitation light for 26NCA films. The excitation slit and emission slit were set to be $10.0 / 10.0 \mathrm{~nm}, 10.0 / 5.0 \mathrm{~nm}$, and $5.0 / 5.0 \mathrm{~nm}$ with $270 \mathrm{~nm}$ excitation light for 26NCA/In layer films. The 


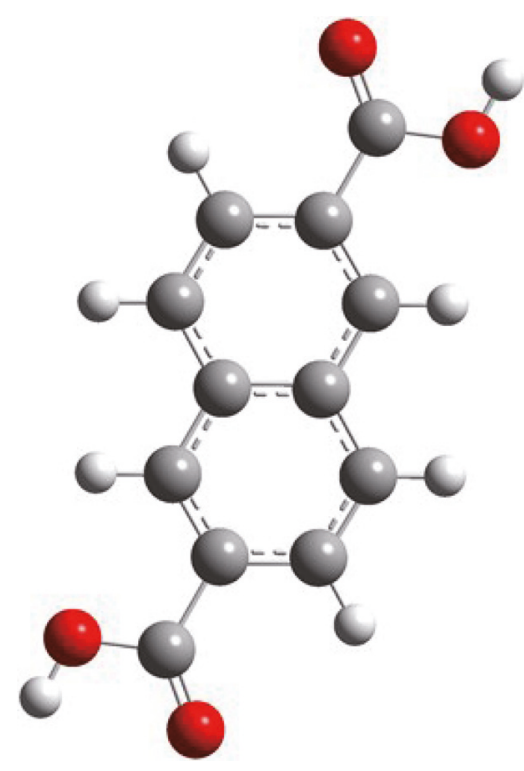

(a)

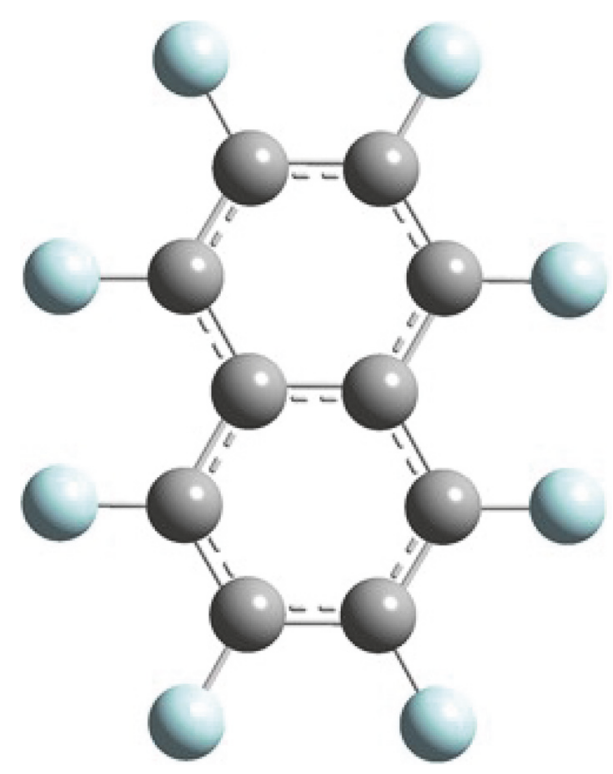

(b)

Figure 1: Molecular structures of 26NCA (a) and OFN (b).

excitation slit and emission slit were set to be $20.0 / 20.0 \mathrm{~nm}$ and $10.0 / 5.0 \mathrm{~nm}$ with $240 \mathrm{~nm}$ or $270 \mathrm{~nm}$ excitation light for $26 \mathrm{NCA} / \mathrm{OFN}$ layer films and $60 \mathrm{~nm} / 1800 \mathrm{~nm}$ 26NCA/OFN film. The excitation slit and emission slit were both set to be $5.0 \mathrm{~nm}$ with $270 \mathrm{~nm}$ excitation light for 26NCA 10-layer film. The excitation slit and emission slit were both set to be $5.0 \mathrm{~nm}$ with $270 \mathrm{~nm}$ excitation light for 26NCA/OFN 10-layer film. The excitation slit and emission slit were both set to be $2.5 \mathrm{~nm}$ with $270 \mathrm{~nm}$ excitation light for raw pristine 26NCA. The excitation slit and emission slit were set to be $2.5 / 1.0 \mathrm{~nm}$ with $270 \mathrm{~nm}$ excitation light for pristine OFN.

\section{Results and Discussion}

Metal In (mp: $157^{\circ} \mathrm{C}$ ), which is mainly used in the manufacture of displayers, such as liquid crystal displayer and flat screen, and OFN (mp: $87^{\circ} \mathrm{C}$ ) with excellent planarity, which is a representative fluorine-containing compound (Figure 1), are chosen as the conformers for 26NCA (mp: $313^{\circ} \mathrm{C}$ ) to prepare tunable blue fluorescence composite films. Meanwhile, the luminescence of single-component metallic In and organic 26NCA was also investigated by preparing single-component film based on LVPVDM.

3.1. Fluorescence, Structural Study, and Surface Morphology of Single-Component Metallic In Film. $400 \mathrm{~nm}$ In film prepared by LVPVDM shows obvious well-defined ultraviolet and blue fluorescence, while block metal In lacks visible solidstate fluorescence, and the resulting fluorescence emission spectrum is shown in Figure 2, where $400 \mathrm{~nm}$ In film has two $\lambda_{\text {em }}{ }^{\max }$ at $359 \mathrm{~nm}$ and $464 \mathrm{~nm}$. XRD pattern can offer some structure information of materials, and Figure S1 in Supplementary Materials shows the XRD pattern of $400 \mathrm{~nm}$ In film, where $400 \mathrm{~nm}$ In film shows no crystal XRD peak, which means $400 \mathrm{~nm}$ In film presents noncrystal aggregation.

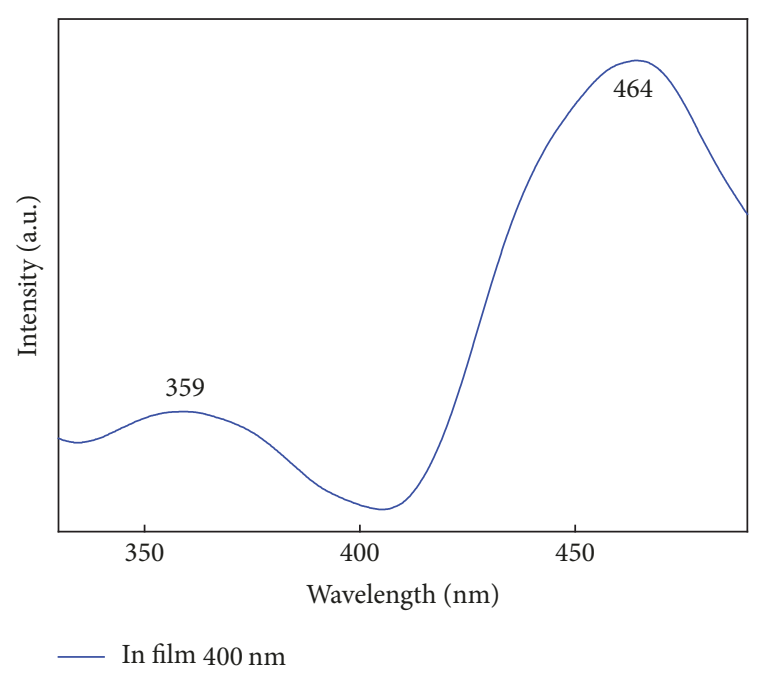

Figure 2: Fluorescence emission spectrum of $400 \mathrm{~nm}$ In film.

Moreover, Figure S2 shows the SEM image of $400 \mathrm{~nm}$ In film without obvious crystal materials, corresponding to the XRD pattern. Significantly, the novel fluorescent behavior of In film may be caused by the noncrystal aggregation.

3.2. Tunable Fluorescence, Structural Study, and Surface Morphology of Single-Component Organic 26NCA Films. 26NCA films and 26NCA 10-layer film exhibit different fluorescent behaviors from that of pristine 26NCA, and the resulting fluorescence emission spectra are shown in Figure 3(a). Pristine 26NCA has two $\lambda_{\mathrm{em}}{ }_{\max }$ at $406 \mathrm{~nm}$ and $426 \mathrm{~nm}$ and one shoulder peak at $445 \mathrm{~nm}$. Compared with pristine $26 \mathrm{NCA}$, the fluorescence emission spectra of 26NCA films show just one $\lambda_{\mathrm{em}}{ }^{\max }$ at $445 \mathrm{~nm}$, while the two $\lambda_{\mathrm{em}}{ }^{\max }$ at $406 \mathrm{~nm}$ and 


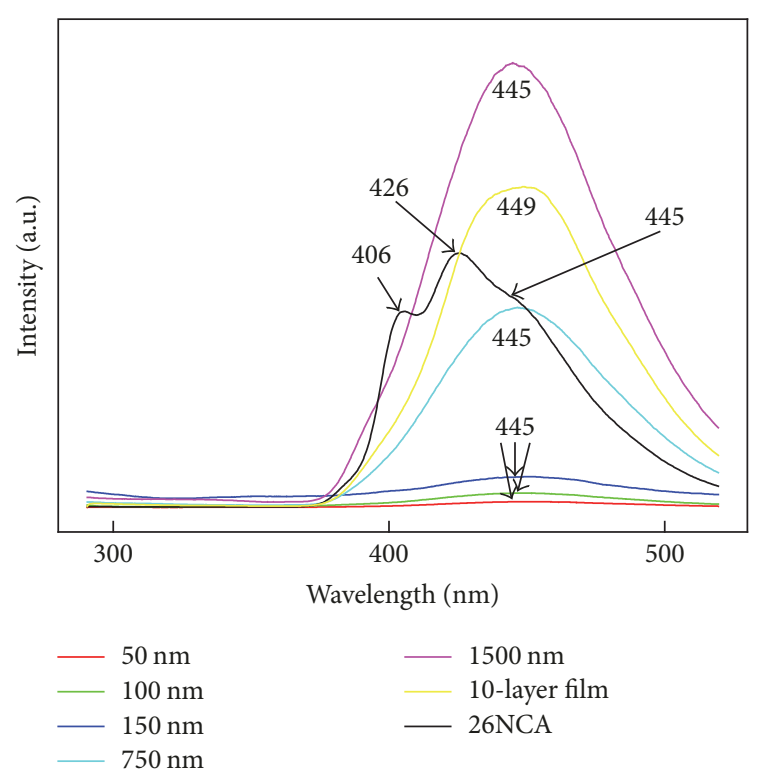

(a)

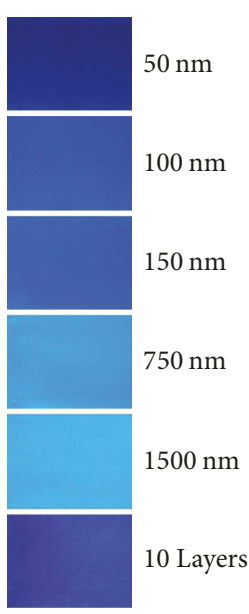

(b)

Figure 3: (a) Fluorescence emission spectra of 26NCA films with different thickness, 26NCA 10-layer film, and pristine 26NCA. (b) Corresponding photographs of 26NCA films under $254 \mathrm{~nm}$ UV.

$426 \mathrm{~nm}$ are no longer observed. Moreover, the fluorescence of all 26NCA films shows no difference in peak shape and peak position except intensity, where the fluorescence emission intensity of 26NCA film intensifies with the increase of 26NCA film's thickness due to the increase of the number of chromophores. In order to improve the fluorescence emission intensity of 26NCA film, 26NCA 10-layer film was designed and prepared, which was $750 \mathrm{~nm}$, where every unit contained $75 \mathrm{~nm}$ 26NCA film. This structure can isolate the interaction between 26NCA molecules to some extent; thus 26NCA crystal will not be fabricated due to the excessive aggregation of 26NCA molecules. Under the same test conditions, 26NCA 10-layer film $(750 \mathrm{~nm})$ shows larger fluorescence emission intensity than the one of $750 \mathrm{~nm} 26 \mathrm{NCA}$ film due to the different preparation technology. 26NCA layer film with excellent fluorescence containing color and intensity can be obtained. The fluorescence emission spectrum of 26NCA 10-layer film shows a red shift about $4 \mathrm{~nm}$ with $\lambda_{\text {em }}{ }^{\max }$ at $449 \mathrm{~nm}$ for the one of pristine 26NCA at $445 \mathrm{~nm}$, while the two $\lambda_{\mathrm{em}}{ }^{\max }$ at $406 \mathrm{~nm}$ and $426 \mathrm{~nm}$ are no longer observed. In addition, the fluorescence emission peak of 26NCA 10layer film slightly broadens. The disappearance of the two $\lambda_{\text {em }}{ }^{\max }$ at $406 \mathrm{~nm}$ and $426 \mathrm{~nm}$ of $26 \mathrm{NCA}$ may be caused by the structural change, which means that transition process changes due to the corresponding energy level structural change.

Figure 3(b) shows the photographs of 26NCA films with different thickness and 26NCA 10-layer film under $254 \mathrm{~nm}$ UV, where all films present blue or cyan fluorescence with different luminance. In addition, the luminescent luminance of 26NCA film intensifies with the increase of 26NCA film's thickness due to the increase of the number of chromophores. Significantly, 26NCA 10-layer film exhibits different fluorescent behavior from that of $750 \mathrm{~nm} \mathrm{26NCA}$ film, where 26NCA 10-layer film presents purplish blue fluorescence, while the $750 \mathrm{~nm}$ 26NCA film presents cyan fluorescence. Moreover, 26NCA 10-layer film shows higher fluorescent emission intensity than the one of $750 \mathrm{~nm} 26 \mathrm{NCA}$ film in Figure 3(a). 26NCA 10-layer film $(750 \mathrm{~nm})$ was prepared by repeating ten times for the preparation of $75 \mathrm{~nm}$ 26NCA film, while $750 \mathrm{~nm}$ 26NCA film was prepared by heating pristine $26 \mathrm{NCA}$ all at once, which means preparation technology would influence the fluorescence of 26NCA film.

Figure S3 shows the resulting XRD pattern of $26 \mathrm{NCA}$ films with different thickness. The two peaks at $15.6^{\circ}$ and $27.0^{\circ}$ have been demonstrated to be the XRD peaks of pristine 26NCA. XRD pattern of 26NCA films is different from the one of pristine $26 \mathrm{NCA}$, where the former shows noncrystal structure, while the latter presents crystal structure. Thus, $\lambda_{\mathrm{em}}^{\max }$ at $406 \mathrm{~nm}$ and $426 \mathrm{~nm}$ of $26 \mathrm{NCA}$ may be caused by the crystal structure of 26NCA, while the shoulder peak at $445 \mathrm{~nm}$ may be caused by the self-structure of 26NCA molecule. This speculation will be demonstrated in many ways below. Figure S4 shows the SEM images of 26NCA films (50 nm and $1500 \mathrm{~nm}$ ), which have micro/nanoscale rhabdolith for 50 and $1500 \mathrm{~nm}$ 26NCA films, where the latter is stacked by sheet structure, corresponding to the XRD pattern.

3.3. Tunable Fluorescence, Structural Study, and Surface Morphology of Two-Component 26NCA/In Layer Films. 26NCA/In layer films with different thickness exhibit different fluorescent behaviors from that of pristine 26NCA, In, 26NCA films, and In film, and the resulting emission spectra are shown in Figure 4. 26NCA/In layer films (26NCA film: $300 \mathrm{~nm}$; In films: $2000 \mathrm{~nm}, 3000 \mathrm{~nm}, 4000 \mathrm{~nm}$, and 


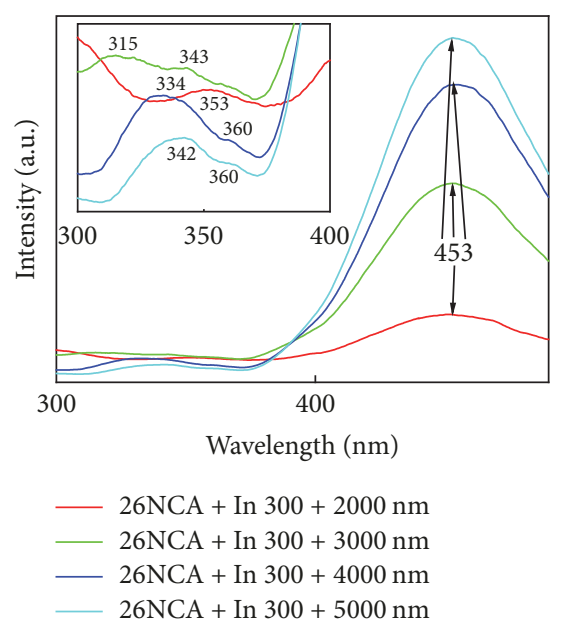

(a)
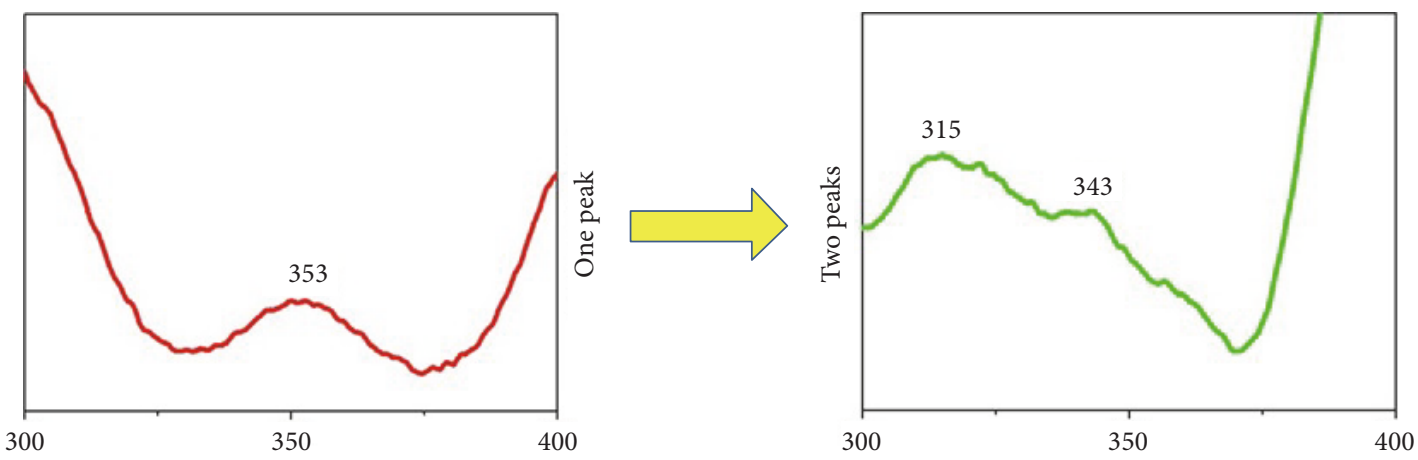

Red shift
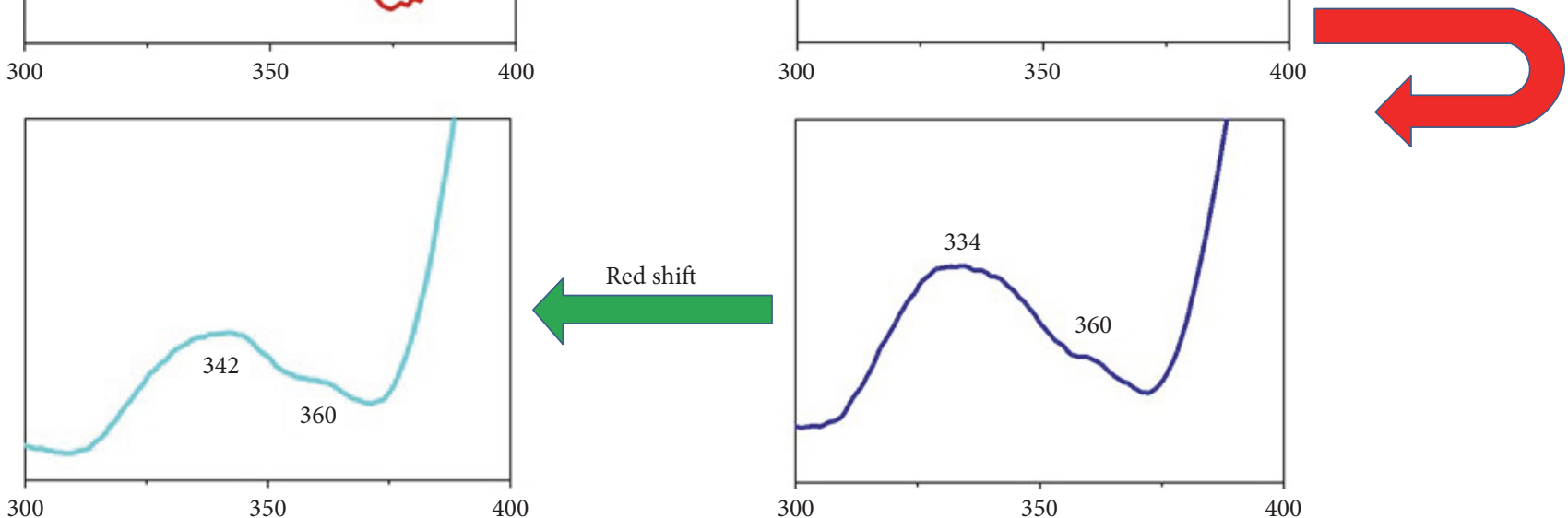

(b)
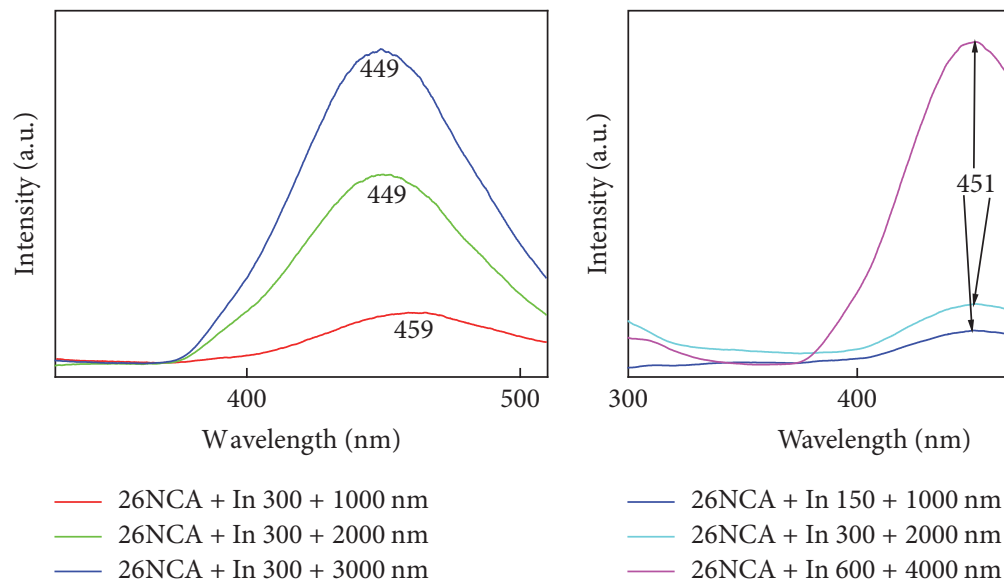

$26 \mathrm{NCA}+$ In $300+1000 \mathrm{~nm}$

$26 \mathrm{NCA}+$ In $300+2000 \mathrm{~nm}$

$26 \mathrm{NCA}+\operatorname{In} 300+2000 \mathrm{~nm}$

- 26NCA + In $300+3000 \mathrm{~nm}$

(c)

(d)

Figure 4: Continued. 


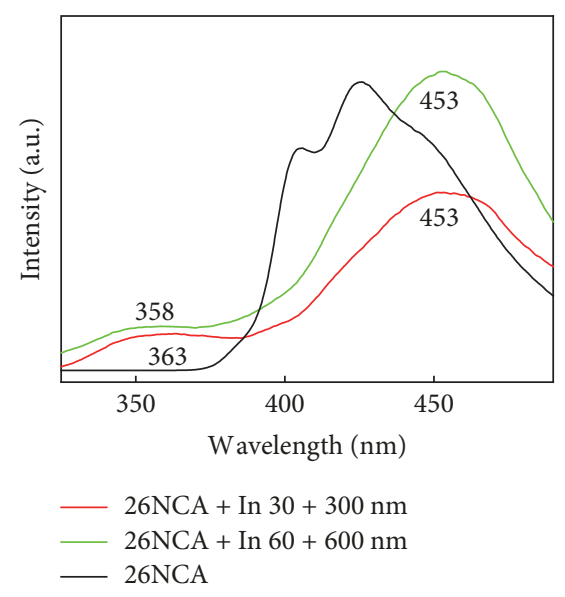

(e)

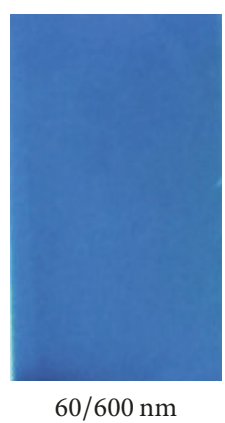

(f)

Figure 4: (a), (c), (d), and (e) Fluorescence emission spectra of 26NCA/In layer films with different thickness and pristine 26NCA. Insert in a) shows the partial enlarged profile. (b) The change in emission wavelength. (f) Photograph of 60/600 nm 26NCA/In film under $254 \mathrm{~nm}$ UV.

$5000 \mathrm{~nm}$ respectively) show tunable multicolor fluorescence. In Figure 4(a), the fluorescence emission spectra show a red shift about $8 \mathrm{~nm}$ with $\lambda_{\mathrm{em}}{ }^{\max }$ at $453 \mathrm{~nm}$ for the one of $26 \mathrm{NCA}$ at $445 \mathrm{~nm}$; moreover, $26 \mathrm{NCA} / \mathrm{In}$ layer films (26NCA film: $300 \mathrm{~nm}$; In films: $2000 \mathrm{~nm}, 3000 \mathrm{~nm}, 4000 \mathrm{~nm}$, and $5000 \mathrm{~nm}$, resp.) show one $\lambda_{\mathrm{em}}{ }^{\max }$ at $353 \mathrm{~nm}$, two $\lambda_{\mathrm{em}}{ }^{\max }$ at $315 \mathrm{~nm}$ and $343 \mathrm{~nm}$, two $\lambda_{\mathrm{em}}{ }^{\max }$ at $334 \mathrm{~nm}$ and $360 \mathrm{~nm}$, and two $\lambda_{\mathrm{em}}{ }_{\max }$ at $342 \mathrm{~nm}$ and $360 \mathrm{~nm}$, respectively, while the two $\lambda_{\mathrm{em}}{ }_{\max }$ at $406 \mathrm{~nm}$ and $426 \mathrm{~nm}$ are no longer observed. In addition, the fluorescence emission intensity at $453 \mathrm{~nm}$ intensifies with the increase of In film's thickness, which may be caused by the acceleration from In film. Figure 4(b) shows the change in emission wavelength. For 26NCA/In layer films (26NCA film: $300 \mathrm{~nm}$; In films: $2000 \mathrm{~nm}, 3000 \mathrm{~nm}, 4000 \mathrm{~nm}$, and $5000 \mathrm{~nm}$ resp.), the fluorescence emission peaks change with the increase of In film's thickness, including the number of emission peak and emission wavelength, which means potential application in the fields of multicolor luminescence and thickness-optical response sensors. In order to avoid the excessive aggregation of In atoms, 26NCA/In layer films (26NCA film: $300 \mathrm{~nm}$; In films: $1000 \mathrm{~nm}, 2000 \mathrm{~nm}$, and $3000 \mathrm{~nm}$, resp.) were designed and prepared, where every In film unit was $1000 \mathrm{~nm}$, which meant $2000 \mathrm{~nm}$ and $3000 \mathrm{~nm}$ In films were prepared by repeating two and three times, respectively, for the preparation of $1000 \mathrm{~nm}$ In film. This structure can isolate the interaction between In atoms to some extent; thus In crystal will not be fabricated due to the excessive aggregation of In atoms. In Figure 4(c), compared with pristine $26 \mathrm{NCA}$, the fluorescence emission spectra show a red shift about $4 \mathrm{~nm}$ with $\lambda_{\mathrm{em}}{ }^{\max }$ at $449 \mathrm{~nm}$ for $26 \mathrm{NCA} / \mathrm{In}$ layer films (26NCA film: $300 \mathrm{~nm}$; In films: $2000 \mathrm{~nm}$ and $3000 \mathrm{~nm}$ ) and a red shift about $14 \mathrm{~nm}$ with $\lambda_{\text {em }}{ }^{\max }$ at $459 \mathrm{~nm}$ for $26 \mathrm{NCA} / \mathrm{In}$ layer film $(300 \mathrm{~nm} / 1000 \mathrm{~nm})$, while the two $\lambda_{\mathrm{em}}{ }^{\max }$ at $406 \mathrm{~nm}$ and $426 \mathrm{~nm}$ are no longer observed. Moreover, the fluorescence emission intensity of 26NCA/In layer film intensifies with the increase of In film's thickness too. The thickness of 26NCA film and In film changes together to tune the fluorescence of 26NCA/In layer film in Figure 4(d).
The fluorescence emission spectra show a red shift about $6 \mathrm{~nm}$ with $\lambda_{\mathrm{em}}{ }^{\max }$ at $451 \mathrm{~nm}$ for the one of 26NCA at $445 \mathrm{~nm}$. Moreover, the fluorescence emission intensity of $26 \mathrm{NCA} / \mathrm{In}$ layer films (26NCA/In: $150 \mathrm{~nm} / 1000 \mathrm{~nm}, 300 \mathrm{~nm} / 2000 \mathrm{~nm}$, and $600 \mathrm{~nm} / 4000 \mathrm{~nm}$ ) intensifies with the increase of $26 \mathrm{NCA}$ and In film's thickness due to the increase of the number of chromophores and possible acceleration from In film. In order to achieve tunable multicolor fluorescence, $26 \mathrm{NCA} / \mathrm{In}$ layer films (26NCA/In: $30 \mathrm{~nm} / 300 \mathrm{~nm}$ and $60 \mathrm{~nm} / 600 \mathrm{~nm}$ ) were designed and fabricated. Significantly, in Figure 4(e), $30 \mathrm{~nm} / 300 \mathrm{~nm}$ and $60 \mathrm{~nm} / 600 \mathrm{~nm}$ 26NCA/In layer films both present two-color emission, where the former shows a red shift about $8 \mathrm{~nm}$ with $\lambda_{\text {em }}{ }^{\max }$ at $453 \mathrm{~nm}$ for the one of 26NCA at $445 \mathrm{~nm}$ and a weaker $\lambda_{\mathrm{em}}{ }^{\max }$ at $363 \mathrm{~nm}$, while the latter shows a red shift about $8 \mathrm{~nm}$ with $\lambda_{\mathrm{em}}{ }_{\max }$ at $453 \mathrm{~nm}$ and a weaker $\lambda_{\text {em }}{ }^{\max }$ at $358 \mathrm{~nm}$. Although the fluorescence emission spectra are different for all 26NCA/In layer films in this paper, $\lambda_{\mathrm{em}}{ }^{\max }$ of $26 \mathrm{NCA}$ at $445 \mathrm{~nm}$ can always be observed, whatever the redshift, which further demonstrates that the shoulder peak at $445 \mathrm{~nm}$ of $26 \mathrm{NCA}$ is caused by the self-structure of 26NCA molecule. Moreover, Figure 4(f) shows the photograph of $60 / 600 \mathrm{~nm} 26 \mathrm{NCA} / \mathrm{In}$ film under $254 \mathrm{~nm}$ UV, presenting blue fluorescence.

In two two-color emission films, $60 \mathrm{~nm} / 600 \mathrm{~nm}$ $26 \mathrm{NCA} / \mathrm{In}$ film may show better crystal form due to bigger thickness, where the intensity of $\lambda_{\mathrm{em}}^{\max }$ at $358 \mathrm{~nm}$ is similar to the one at $453 \mathrm{~nm}$, just 6.3 folds, for $60 \mathrm{~nm} / 600 \mathrm{~nm}$ $26 \mathrm{NCA} / \mathrm{In}$ layer film, while the intensity of $\lambda_{\mathrm{em}}{ }^{\max }$ at $363 \mathrm{~nm}$ is similar to the one at $453 \mathrm{~nm}$, just 4.6 folds, for $30 \mathrm{~nm} / 300 \mathrm{~nm}$ 26NCA/In layer film. Figure S5 shows the XRD pattern of $60 \mathrm{~nm} / 600 \mathrm{~nm} 26 \mathrm{NCA} / \mathrm{In}$ layer film, which exhibits noncrystal due to the thin 26NCA film and In film. $\lambda_{\text {em }}{ }^{\max }$ at $445 \mathrm{~nm}$ of $26 \mathrm{NCA} / \mathrm{In}$ layer film is caused by noncrystal 26NCA instead of In, which further demonstrates that the shoulder peak at $445 \mathrm{~nm}$ is caused by the self-structure of 26NCA molecule.

Figure S6 shows SEM image of $60 \mathrm{~nm} / 600 \mathrm{~nm}$ 26NCA/In layer film, which have no obvious crystal materials, just 
stack of 26NCA or In, corresponding to the XRD pattern, exhibiting low crystallinity. Significantly, the SEM image and XRD pattern of $60 \mathrm{~nm} / 600 \mathrm{~nm}$ 26NCA/In layer film further demonstrate that $\lambda_{\mathrm{em}}{ }^{\max }$ at $445 \mathrm{~nm}$ of 26NCA films and 26NCA/In layer films is caused by the self-structure of 26NCA molecule instead of the crystal structure of 26NCA.

3.4. Tunable Fluorescence, Structural Study, and Surface Morphology of Two-Component 26NCA/OFN Films. 26NCA/ OFN films with different thickness exhibit different fluorescent behaviors from that of pristine 26NCA, OFN, and 26NCA films, and the resulting emission spectra are shown in Figure 5. 26NCA/OFN layer films (26NCA film: $60 \mathrm{~nm}$; OFN films: $1800 \mathrm{~nm}, 2700 \mathrm{~nm}$, and $3600 \mathrm{~nm}$, resp.) show tunable multicolor fluorescence. In Figure 5(a), the fluorescence emission spectra show a red shift about $15 \mathrm{~nm}$ with $\lambda_{\text {em }}{ }^{\max }$ at $460 \mathrm{~nm}$ for $60 \mathrm{~nm} / 1800 \mathrm{~nm}$ 26NCA/OFN layer film and a red shift about $9 \mathrm{~nm}$ with $\lambda_{\mathrm{em}}{ }^{\max }$ at $454 \mathrm{~nm}$ both for $60 \mathrm{~nm} / 2700 \mathrm{~nm}$ and for $60 \mathrm{~nm} / 3600 \mathrm{~nm} 26 \mathrm{NCA} / \mathrm{OFN}$ layer films for the one of $26 \mathrm{NCA}$ at $445 \mathrm{~nm}$. Moreover, in Figure 5(a), the insert is the partial enlarged pattern; 26NCA/OFN layer films (26NCA film: $60 \mathrm{~nm}$; OFN films: $1800 \mathrm{~nm}, 2700 \mathrm{~nm}$, and $3600 \mathrm{~nm}$, resp.) show two $\lambda_{\mathrm{em}}{ }^{\max }$ at $310 \mathrm{~nm}$ and $353 \mathrm{~nm}$, one $\lambda_{\text {em }}{ }^{\max }$ at $341 \mathrm{~nm}$, and two $\lambda_{\mathrm{em}}{ }^{\max }$ at $301 \mathrm{~nm}$ and $358 \mathrm{~nm}$, respectively, under $240 \mathrm{~nm}$ excitation light, while the two $\lambda_{\mathrm{em}}^{\max }$ at $406 \mathrm{~nm}$ and $426 \mathrm{~nm}$ are no longer observed. In addition, the fluorescence emission intensity intensifies with the increase of OFN film's thickness, which may be caused by the acceleration from OFN film. Figure 5(b) shows the change in emission wavelength. The fluorescence emission peaks change with the increase of OFN film's thickness, including the number of emission peak and emission wavelength. Significantly, the switch among three spectra in Figure 5(b) may mean a thickness-optical response, which means two potential applications in multicolor luminescent device and thickness-optical response sensor. In order to avoid the excessive aggregation of OFN molecules, 26NCA/OFN layer films (26NCA film: $60 \mathrm{~nm}$; OFN films: $60 \mathrm{~nm}, 600 \mathrm{~nm}, 900 \mathrm{~nm}$, and $1200 \mathrm{~nm}$, resp.) were prepared. This structure can isolate the interaction between OFN molecules to some extent due to the fewer OFN molecules; thus OFN crystal will not be fabricated due to the excessive aggregation of OFN molecules. In Figure 5(c), compared with pristine 26NCA, the fluorescence emission spectra show a red shift about $9 \mathrm{~nm}$ with $\lambda_{\mathrm{em}}{ }^{\max }$ at $454 \mathrm{~nm}$ for $60 \mathrm{~nm} / 1200 \mathrm{~nm}$ 26NCA/OFN layer film and a red shift about $7 \mathrm{~nm}$ with $\lambda_{\mathrm{em}}{ }^{\max }$ at $452 \mathrm{~nm}$ for $26 \mathrm{NCA} / \mathrm{OFN}$ layer films (26NCA film: $60 \mathrm{~nm}$; OFN films: $60 \mathrm{~nm}, 600 \mathrm{~nm}$, and $900 \mathrm{~nm}$, resp.), while the two $\lambda_{\mathrm{em}}{ }^{\max }$ at $406 \mathrm{~nm}$ and $426 \mathrm{~nm}$ are no longer observed. In addition, the fluorescence emission intensity of 26NCA/OFN layer film intensifies with the increase of OFN film's thickness too due to the possible acceleration from OFN film. The thickness of 26NCA film and OFN film changes together to tune the fluorescence of 26NCA/OFN layer film in Figure 5(d). The fluorescence emission spectra show a red shift about $7 \mathrm{~nm}$ with $\lambda_{\mathrm{em}}{ }^{\max }$ at $452 \mathrm{~nm}$ for the one of $26 \mathrm{NCA}$ at $445 \mathrm{~nm}$; moreover, the fluorescence emission intensity of 26NCA/OFN layer film decreases with the increase of 26NCA and OFN film's thickness. In order to achieve tunable multicolor fluorescence, $60 \mathrm{~nm} / 1800 \mathrm{~nm}$ 26NCA/OFN film was fabricated, where the film was prepared by heating the mixture including 26NCA and OFN with suitable stoichiometric ratio. Significantly, in Figure 5(e), the spectrum presents two fluorescence emission peaks including a red shift about $6 \mathrm{~nm}$ with $\lambda_{\mathrm{em}}{ }^{\max }$ at $451 \mathrm{~nm}$ for the one of 26NCA at $445 \mathrm{~nm}$ and a weaker $\lambda_{\text {em }}{ }^{\max }$ at $353 \mathrm{~nm}$, where the intensity of $\lambda_{\mathrm{em}}{ }^{\max }$ at $445 \mathrm{~nm}$ is similar to the one at $353 \mathrm{~nm}$, just 2.2 folds, which will promote the development of new generation multicolor luminescent devices. In view of the planarity of 26NCA and OFN molecules, especially for OFN molecule, 26NCA/OFN 10-layer film was fabricated. In Figure 5(f), compared with pristine $26 \mathrm{NCA}$, the fluorescence emission spectra show a red shift about $2 \mathrm{~nm}$ with $\lambda_{\mathrm{em}}{ }^{\max }$ at $447 \mathrm{~nm}$ and a shoulder peak at $398 \mathrm{~nm}$, which means a potential application in layered materials. Figures $5(\mathrm{~g})$ and $5(\mathrm{~h})$ show the photographs of $60 \mathrm{~nm} / 900 \mathrm{~nm}$ 26NCA/OFN layer film and 26NCA/OFN 10layer film under $254 \mathrm{~nm} \mathrm{UV}$, where the two films present blue fluorescence, which is similar to the one of 26NCA 10 layers film, due to the similar preparation technology.

Figure S7 shows the resulting XRD pattern of $60 \mathrm{~nm} / 900 \mathrm{~nm} 26 \mathrm{NCA} / \mathrm{OFN}$ layer film. The peak at $15.6^{\circ}$ has been demonstrated to be the XRD peak of pristine $26 \mathrm{NCA}$. XRD patterns of $60 \mathrm{~nm} / 900 \mathrm{~nm}$ 26NCA/OFN layer film are completely different from the one of 26NCA and OFN, where the former show noncrystal structure not only due to the thin film but also due to the process, lacking enough time to crystallize, while the latter present crystal structure (Figure S8). Significantly, the speculation further demonstrated that $\lambda_{\text {em }}{ }^{\max }$ at $406 \mathrm{~nm}$ and $426 \mathrm{~nm}$ of $26 \mathrm{NCA}$ is caused by the crystal structure of 26NCA, while the shoulder peak at $445 \mathrm{~nm}$ is caused by the self-structure of 26NCA molecule.

Figure S9 shows the SEM image of $60 \mathrm{~nm} / 900 \mathrm{~nm}$ 26NCA/OFN layer film, which have no obvious crystal materials, just stack of 26NCA or OFN molecule, corresponding to the XRD pattern, exhibiting low crystallinity. Significantly, the SEM image further demonstrates that $\lambda_{\mathrm{em}}{ }_{\max }$ at $445 \mathrm{~nm}$ of $26 \mathrm{NCA} / \mathrm{OFN}$ layer films is caused by the self-structure of 26NCA molecule instead of the crystal structure of 26NCA, which means that $\lambda_{\mathrm{em}}{ }^{\max }$ at $406 \mathrm{~nm}$ and $426 \mathrm{~nm}$ of $26 \mathrm{NCA}$ is caused by the crystal structure of $26 \mathrm{NCA}$, while the shoulder peak at $445 \mathrm{~nm}$ of $26 \mathrm{NCA}$ is caused by the self-structure of 26NCA molecule.

Figure S10 shows the resulting XRD pattern of 26NCA/OFN 10-layer film without any X-ray diffraction peak. The film shows noncrystal structure not only due to the thin film but also due to the process, lacking enough time to crystallize. Significantly, the speculation further demonstrated that $\lambda_{\mathrm{em}}{ }^{\max }$ at $406 \mathrm{~nm}$ and $426 \mathrm{~nm}$ of $26 \mathrm{NCA}$ is caused by the crystal structure of $26 \mathrm{NCA}$, while the shoulder peak at $445 \mathrm{~nm}$ is caused by the self-structure of 26NCA molecule.

Figure S11 shows the SEM image of 26NCA/OFN 10-layer film, which has no obvious crystal materials, just stack of 26NCA or OFN molecule, corresponding to the XRD pattern, exhibiting low crystallinity. Significantly, the SEM image further demonstrates that $\lambda_{\mathrm{em}}{ }^{\max }$ at $445 \mathrm{~nm}$ of $26 \mathrm{NCA} / \mathrm{OFN}$ layer films is caused by the self-structure of 26NCA molecule 


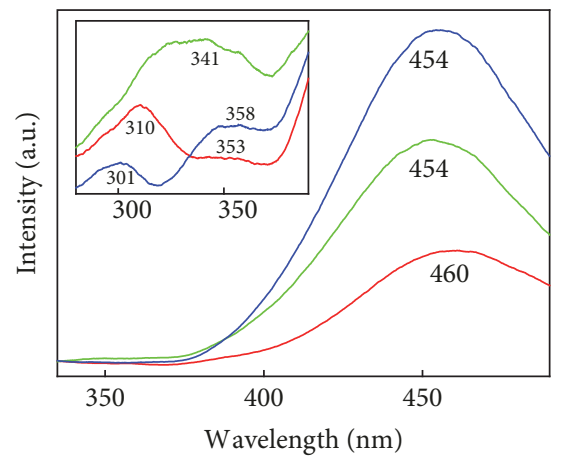

$-26 \mathrm{NCA}+$ OFN $60+1800 \mathrm{~nm}$

- $26 \mathrm{NCA}+$ OFN $60+2700 \mathrm{~nm}$

- $26 \mathrm{NCA}+$ OFN $60+3600 \mathrm{~nm}$

(a)
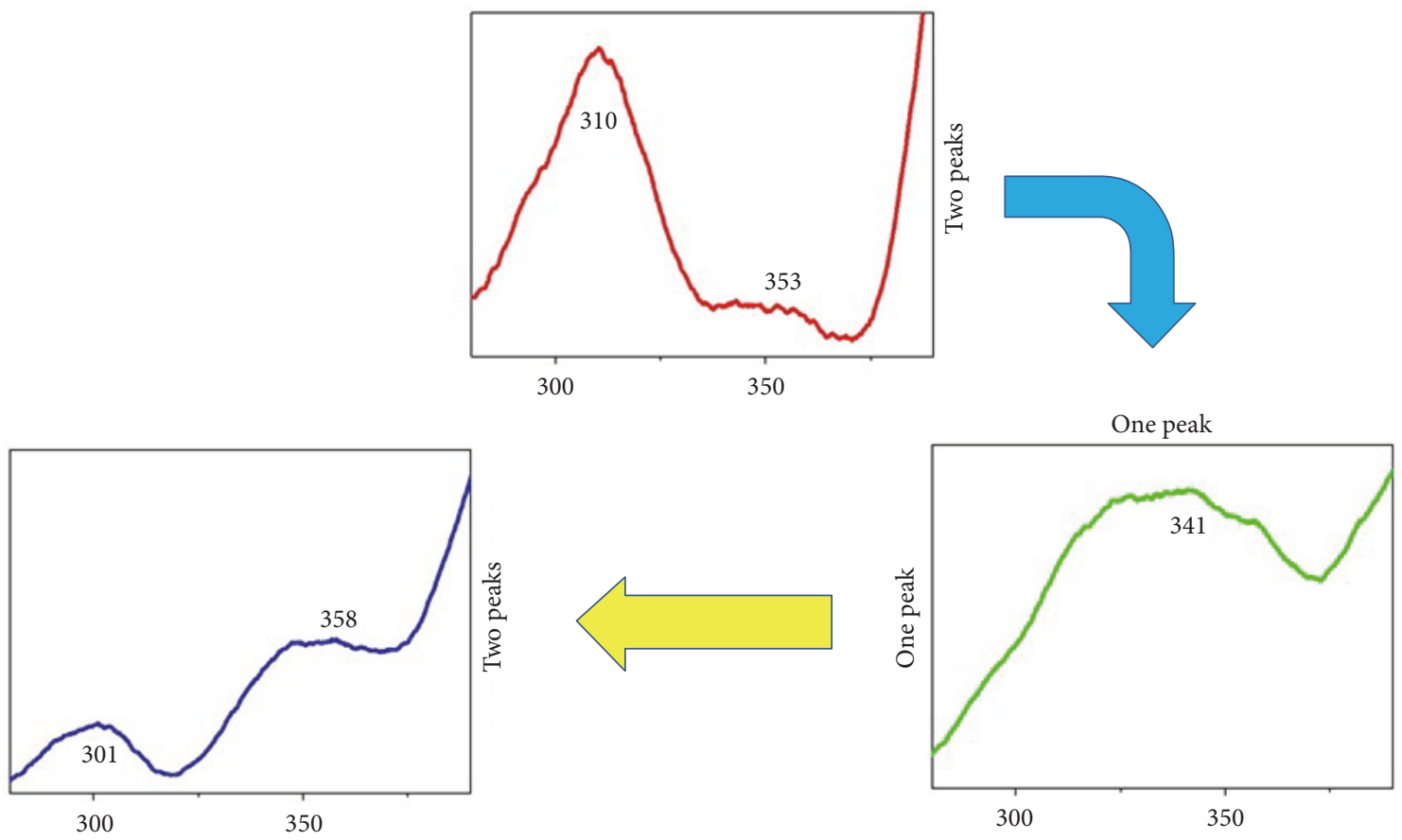

(b)
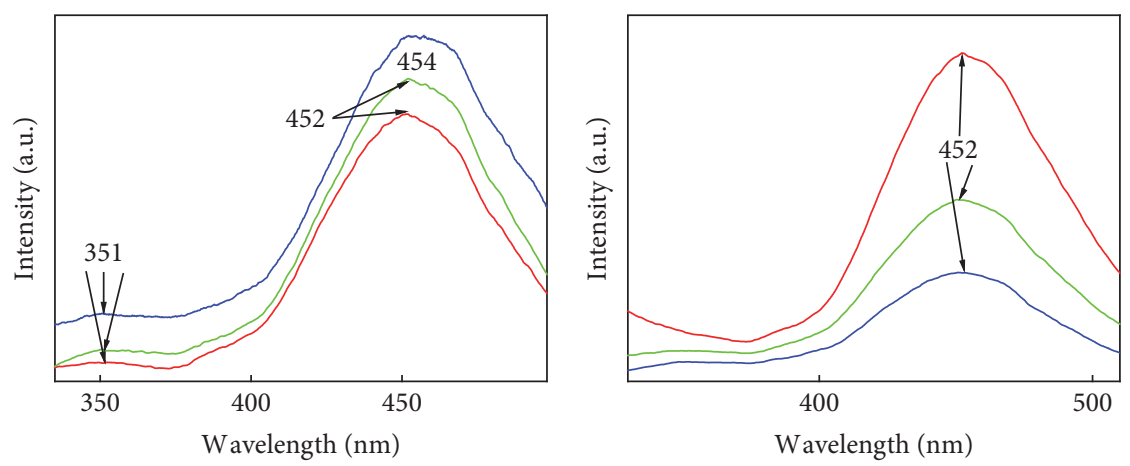

$\begin{array}{ll}- & 26 \mathrm{NCA}+\text { OFN } 60+600 \mathrm{~nm} \\ - & 26 \mathrm{NCA}+\text { OFN } 60+900 \mathrm{~nm} \\ - & 26 \mathrm{NCA}+\text { OFN } 60+1200 \mathrm{~nm}\end{array}$

(c)
- $26 \mathrm{NCA}+\mathrm{OFN} 20+20 \mathrm{~nm}$

$26 \mathrm{NCA}+$ OFN $40+40 \mathrm{~nm}$

$26 \mathrm{NCA}+\mathrm{OFN} 60+60 \mathrm{~nm}$

(d)

Figure 5: Continued. 


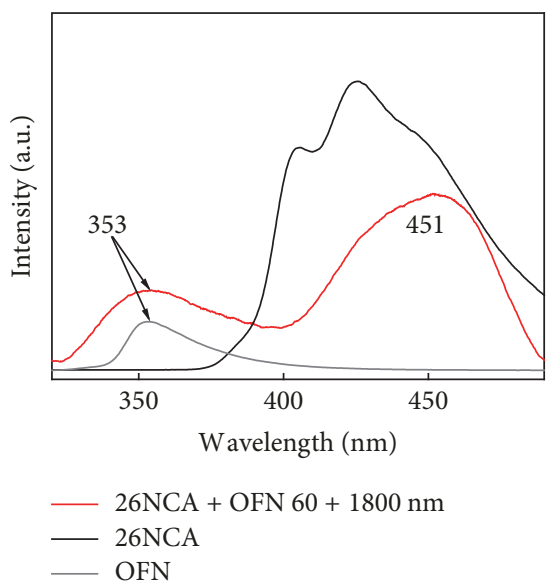

(e)

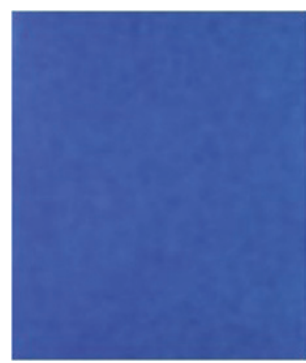

$60 / 900 \mathrm{~nm}$

(g)

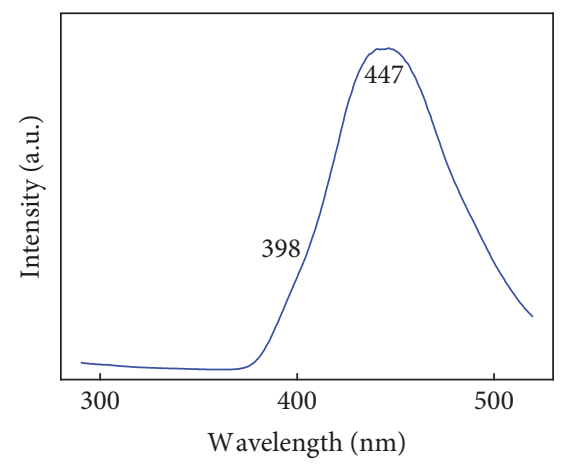

_ 26NCA OFN 10-layer film

(f)

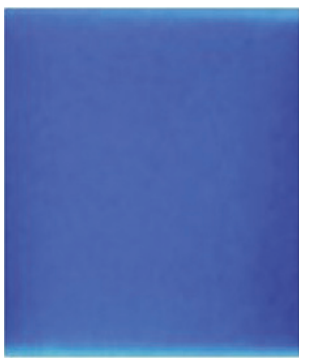

10 Layers

(h)

Figure 5: (a), (c), (d), (e), and (f) Fluorescence emission spectra of 26NCA/OFN layer films with different thickness, 26NCA/OFN 10-layer film, and pristine 26NCA and OFN. Insert in (a) shows the partial enlarged profile. (b) The change in emission wavelength. (g) and (h) Photographs of 60/900 $\mathrm{nm}$ 26NCA/OFN film and 10-layer film under $254 \mathrm{~nm} \mathrm{UV}$.

instead of the crystal structure of 26NCA, which means that $\lambda_{\mathrm{em}}{ }^{\max }$ at $406 \mathrm{~nm}$ and $426 \mathrm{~nm}$ of $26 \mathrm{NCA}$ is caused by the crystal structure of $26 \mathrm{NCA}$, while the shoulder peak at $445 \mathrm{~nm}$ of $26 \mathrm{NCA}$ is caused by the self-structure of $26 \mathrm{NCA}$ molecule.

\section{Conclusion}

Single-component metallic In film and organic 26NCA film and two-component films of 26NCA/In and 26NCA/OFN have been fabricated by LVPVDM with some changed properties, such as material structure and fluorescence. Interestingly, fluorescence can be obtained for In film, while the bulk In shows no fluorescent behavior at all. In addition, compared with pristine bulk In, 26NCA, and OFN, 26NCA films, 26NCA/In films, and 26NCA/OFN films show novel fluorescence, including not only changes in shape and intensity of fluorescence emission spectra, but also changes in fluorescent response, which means potential application in the fields of multicolor luminescent devices, thicknessoptical response sensors, flexible and soft optical devices, and even large-scale flat display devices. Meanwhile, the speculation is demonstrated in many ways that $\lambda_{\mathrm{em}}{ }^{\max }$ at $406 \mathrm{~nm}$ and $426 \mathrm{~nm}$ of 26NCA may be caused by the crystal structure of 26NCA, while the shoulder peak at $445 \mathrm{~nm}$ may be caused by the self-structure of 26NCA molecule.
Importantly, LVPVDM is proved to be a capable way to prepare single/multicomponent metallic/organic luminescent film materials. Moreover, LVPVDM is also anticipated to prepare single/multicomponent metallic/organic lightemitting materials, which can be utilized in large-scale flat panel display and soft optical device, such as film materials and next generation of photofunctional materials.

\section{Conflicts of Interest}

The authors declare no competing financial interests.

\section{Authors' Contributions}

Qingyun Meng, Xiaoyu Zhai, and Yun Wang have conceived and designed the experiments; Yufeng Ding, Xiaoyu Zhai, Liangliang Pan, Siqi Li, Huimei He, Dapeng Zhang, Xinyue $\mathrm{Hu}$, and Ruoyu Zhang have performed the fabrications and characterizations; Yufeng Ding and Xiaoyu Zhai have interpreted the data and cowrote the paper.

\section{Acknowledgments}

The authors would like to thank all the coworkers cited in the references below for their invaluable contributions to the work described here. 


\section{Supplementary Materials}

Figure S1: XRD pattern of $400 \mathrm{~nm}$ In film. Figure S2: SEM image of $400 \mathrm{~nm}$ In film. Figure S3: XRD patterns of 26NCA films with different thickness. Figure S4: SEM images of 26NCA films (left: $50 \mathrm{~nm}$ and right: $1500 \mathrm{~nm}$ ). Figure S5: XRD pattern of $60 \mathrm{~nm} / 600 \mathrm{~nm} 26 \mathrm{NCA} / \mathrm{In}$ layer film. Figure S6: SEM image of $60 \mathrm{~nm} / 600 \mathrm{~nm}$ 26NCA/In layer film. Figure S7: XRD pattern of $60 \mathrm{~nm} / 900 \mathrm{~nm} 26 \mathrm{NCA} / \mathrm{OFN}$ layer film. Figure S8: XRD patterns of pristine 26NCA and OFN. Figure S9: SEM image of $60 \mathrm{~nm} / 900 \mathrm{~nm}$ 26NCA/OFN layer film. Figure S10: XRD pattern of 26NCA/OFN 10-layer film. Figure S11: SEM image of 26NCA/OFN 10-layer film. (Supplementary Materials)

\section{References}

[1] R. H. Friend, R. W. Gymer, A. B. Holmes et al., "Electroluminescence in conjugated polymers," Nature, vol. 397, no. 6715, pp. 121-128, 1999.

[2] S. Tu, S. H. Kim, J. Joseph, D. A. Modarelli, and J. R. Parquette, "Self-assembly of a donor-acceptor nanotube. a strategy to create bicontinuous arrays," Journal of the American Chemical Society, vol. 133, no. 47, pp. 19125-19130, 2011.

[3] Y. Che and L. Zang, "Enhanced fluorescence sensing of amine vapor based on ultrathin nanofibers," Chemical Communications, no. 34, pp. 5106-5108, 2009.

[4] Z. Ning, Z. Chen, Q. Zhang et al., "Aggregation-induced emission (AIE)-active starburst triarylamine fluorophores as potential non-doped red emitters for organic light-emitting diodes and $\mathrm{Cl}_{2}$ gas chemodosimeter," Advanced Functional Materials, vol. 17, no. 18, pp. 3799-3807, 2007.

[5] Y. Sagara and T. Kato, "Mechanically induced luminescence changes in molecular assemblies," Nature Chemistry, vol. 1, pp. 605-610, 2009.

[6] D. Yan, J. Lu, J. Ma et al., "Layered host-guest materials with reversible piezochromic luminescence," Angewandte Chemie International Edition, vol. 50, no. 31, pp. 7037-7040, 2011.

[7] D. Yan, J. Lu, J. Ma, M. Wei, D. G. Evans, and X. Duan, "Reversibly thermochromic, fluorescent ultrathin films with a supramolecular architecture," Angewandte Chemie International Edition, vol. 50, no. 3, pp. 720-723, 2011.

[8] N. Tessler, V. Medvedev, M. Kazes, S. Kan, and U. Banin, "Efficient near-infrared polymer nanocrystal light-emitting diodes," Science, vol. 295, no. 5559, pp. 1506-1508, 2002.

[9] T. Cheng, Y. Xu, S. Zhang, W. Zhu, X. Qian, and L. Duan, “A highly sensitive and selective OFF-ON fluorescent sensor for cadmium in aqueous solution and living cell," Journal of the American Chemical Society, vol. 130, no. 48, pp. 16160-16161, 2008.

[10] K. Kundu, S. F. Knight, N. Willett, S. Lee, W. R. Taylor, and N. Murthy, "Hydrocyanines: A class of fluorescent sensors that can image reactive oxygen species in cell culture, tissue, and in vivo," Angewandte Chemie International Edition, vol. 48, no. 2, pp. 299-303, 2009.

[11] F. J. Hoeben, P. Jonkheijm, E. W. Meijer, and A. P. Schenning, "About supramolecular assemblies of p-conjugated systems," Chemical Reviews, vol. 105, pp. 1491-1546, 2005.

[12] Y. Sun, K. Ye, H. Zhang et al., "Luminescent one-dimensional nanoscale materials with Pt II. . PtII interactions," Angewandte Chemie International Edition, vol. 45, no. 34, pp. 5610-5613, 2006.
[13] M. Lescanne, A. Colin, O. Mondain-Monval, K. Heuzé, F. Fages, and J.-L. Pozzo, "Flow-induced alignment of fiberlike supramolecular self-assemblies during organogel formation with various low molecular mass organogelator-solvent systems," Langmuir, vol. 18, no. 19, pp. 7151-7153, 2002.

[14] K. P. Prasad, Y. Chen, M. A. Sk et al., "Fluorescent quantum dots derived from PEDOT and their applications in optical imaging and sensing," Materials Horizons, vol. 1, no. 5, pp. 529-534, 2014.

[15] L. Lu, Y. Shen, X. Chen, L. Qian, and K. Lu, "Ultrahigh strength and high electrical conductivity in copper," Science, vol. 304, no. 5669, pp. 422-426, 2004.

[16] A. P. Alivisatos, P. F. Barbara, A. W. Castleman et al., "From molecules to materials: Current trends and future directions," Advanced Materials, vol. 10, no. 16, pp. 1297-1336, 1998.

[17] P. Ball and L. Garwin, "Science at the atomic scale," Nature, vol. 355, pp. 761-766, 1992.

[18] A. N. Goldstein, C. M. Echer, and A. P. Alivisatos, "Melting in semiconductor nanocrystals," Science, vol. 256, no. 5062, pp. 1425-1427, 1992.

[19] Y. Zhao, H. B. Fu, A. D. Peng, Y. Ma, D. B. Xiao, and J. N. Yao, "Low-dimensional nanomaterials based on small organic molecules: preparation and optoelectronic properties," Advanced Materials, vol. 20, no. 15, pp. 2859-2876, 2008.

[20] D. Yan, H. Yang, Q. Meng, H. Lin, and M. Wei, “Two-component molecular materials of 2,5-diphenyloxazole exhibiting tunable ultraviolet/blue polarized emission, pump-enhanced luminescence, and mechanochromic response," Advanced Functional Materials, vol. 24, no. 5, pp. 587-594, 2014.

[21] H. Zhang, B. Yang, Y. Zheng, G. Yang, L. Ye, and Y. Ma, “Tribological properties of cermets based on nitride/steel mixtures: a.d. panasyuk et al, poroshkovaya metallurgiya, no 2, 1991, 6568," The Journal of Physical Chemistry B, vol. 108, pp. 9571-9573, 2004.

[22] Y. Shinozuka and M. Matsuura, "Wannier exciton in quantum wells," Physical Review B: Condensed Matter and Materials Physics, vol. 28, no. 8, pp. 4878-4881, 1983.

[23] V. S. Vikhnin and S. Kapphan, "Vibronic charge-transfer excitons: Possible nature of the unusual properties of virtual perovskitelike ferroelectrics," Physics of the Solid State, vol. 40, no. 5, pp. 834-836, 1998.

[24] D. Yan, A. Delori, G. O. Lloyd et al., "A cocrystal strategy to tune the luminescent properties of stilbene-type organic solidstate materials," Angewandte Chemie International Edition, vol. 50, no. 52, pp. 12483-12486, 2011.

[25] D. J. Wuest, "Molecular solids: co-crystals give light a tune-up," Nature Chemistry, vol. 4, pp. 74-75, 2012.

[26] D. Yan, A. Delori, G. O. Lloyd et al., "Modification of luminescent properties of a coumarin derivative by formation of multicomponent crystals," CrystEngComm, vol. 14, no. 16, pp. 51215123, 2012.

[27] D. Yan, D.-K. Bučar, A. Delori et al., "Ultrasound-assisted construction of halogen-bonded nanosized cocrystals that exhibit thermosensitive luminescence," Chemistry - A European Journal, vol. 19, no. 25, pp. 8213-8219, 2013.

[28] D. Yan, B. Patel, A. Delori, W. Jones, and X. Duan, "The formation of hydrogen-bond facilitated salts with tunable optical properties: an experimental and theoretical study of 2,4,5triphenylimidazole," Crystal Growth and Design, vol. 13, no. 1, pp. 333-340, 2013.

[29] D. Yan and D. Evans, "Molecular crystalline materials with tunable luminescent properties: from polymorphs to multicomponent solids," Materials Horizons, vol. 1, pp. 46-57, 2014. 
[30] A. Vidyasagar, K. Handore, and K. M. Sureshan, "Soft optical devices from self-healing gels formed by oil and sugar-based organogelators," Angewandte Chemie International Edition, vol. 50, no. 35, pp. 8021-8024, 2011.

[31] R. Van Hameren, P. Schön, A. M. Van Buul et al., "Macroscopic hierarchical surface patterning of porphyrin trimers via selfassembly and dewetting," Science, vol. 314, no. 5804, pp. 14331436, 2006.

[32] A. Ajayaghosh and V. K. Praveen, " $\pi$-organogels of selfassembled p-phenylenevinylenes: Soft materials with distinct size, shape, and functions," Accounts of Chemical Research, vol. 40, no. 8, pp. 644-656, 2007.

[33] G. O. Lloyd and J. W. Steed, "Anion-tuning of supramolecular gel properties," Nature Chemistry, vol. 1, pp. 437-442, 2009.

[34] Z. Zhou, Y. Qin, W. Xu, and D. Zhu, "Supramolecular association behavior of a strong C60 receptor with conjugated pentacene and tetrathiafulvalene moieties in solution and in the solid state," Chemical Communications, vol. 50, no. 31, pp. 40824084, 2014.

[35] J. Luo, T. Lei, L. Wang et al., "Highly fluorescent rigid supramolecular polymeric nanowires constructed through multiple hydrogen bonds," Journal of the American Chemical Society, vol. 131, no. 6, pp. 2076-2077, 2009.

[36] A. L. Briseno, S. C. B. Mannsfeld, S. A. Jenekhe, Z. Bao, and Y. Xia, "Introducing organic nanowire transistors," Materials Today, vol. 11, no. 4, pp. 38-47, 2008.

[37] J. Huang, S. Virji, B. H. Weiller, and R. B. Kaner, "Nanostructured polyaniline sensors," Chemistry, vol. 10, pp. 1314-1319, 2004.

[38] M. S. Wong, C. Bosshard, and P. Güter, "Crystal engineering of molecular NLO materials," Advanced Materials, vol. 9, no. 10, pp. 837-842, 1997.

[39] T.-C. Chao, Y.-T. Lin, C.-Y. Yang et al., "Highly efficient UV organic light-emitting devices based on $\mathrm{Bi}(9,9$-diarylfluorene)s," Advanced Materials, vol. 17, no. 8, pp. 992-996, 2005.

[40] K. Watanabe, T. Taniguchi, and H. Kanda, "Direct-bandgap properties and evidence for ultraviolet lasing of hexagonal boron nitride single crystal," Nature Materials, vol. 3, no. 6, pp. 404-409, 2004.

[41] X. Zhai, S. Li, Y. Ding et al., "Fabrication and Investigation of Two-Component Film of 2,5-Diphenyloxazole and Octafluoronaphthalene Exhibiting Tunable Blue/Bluish Violet Fluorescence Based on Low Vacuum Physical Vapor Deposition Method," Journal of Nanomaterials, vol. 2016, Article ID 4363541, 8 pages, 2016. 


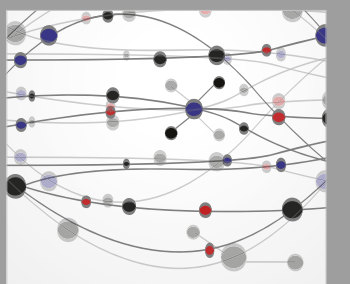

The Scientific World Journal
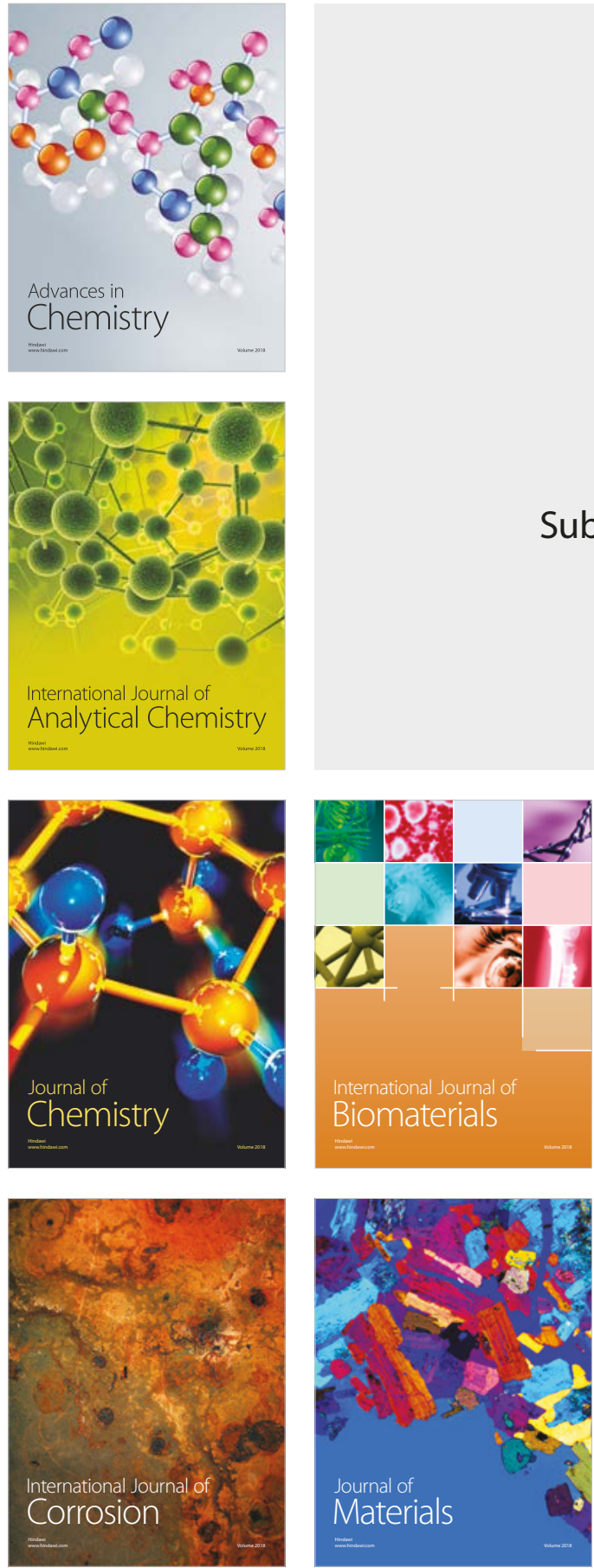

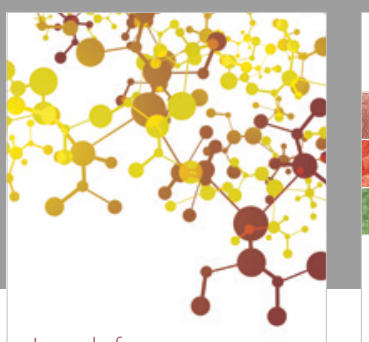

Journal of

Applied Chemistry
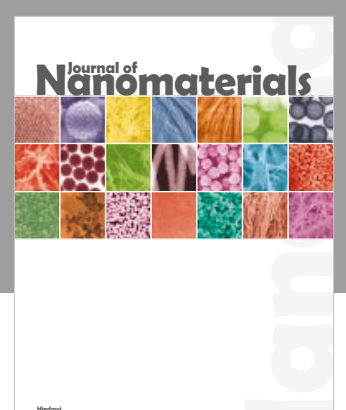

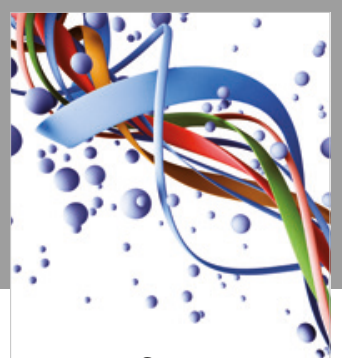

Scientifica

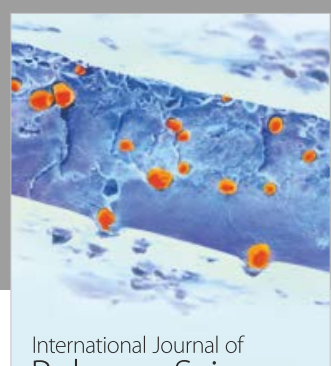

Polymer Science

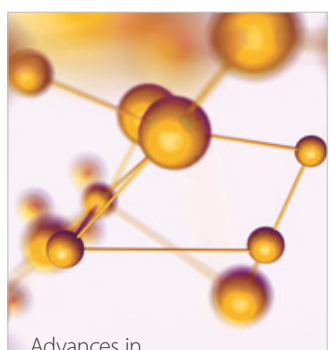

Physical Chemistry
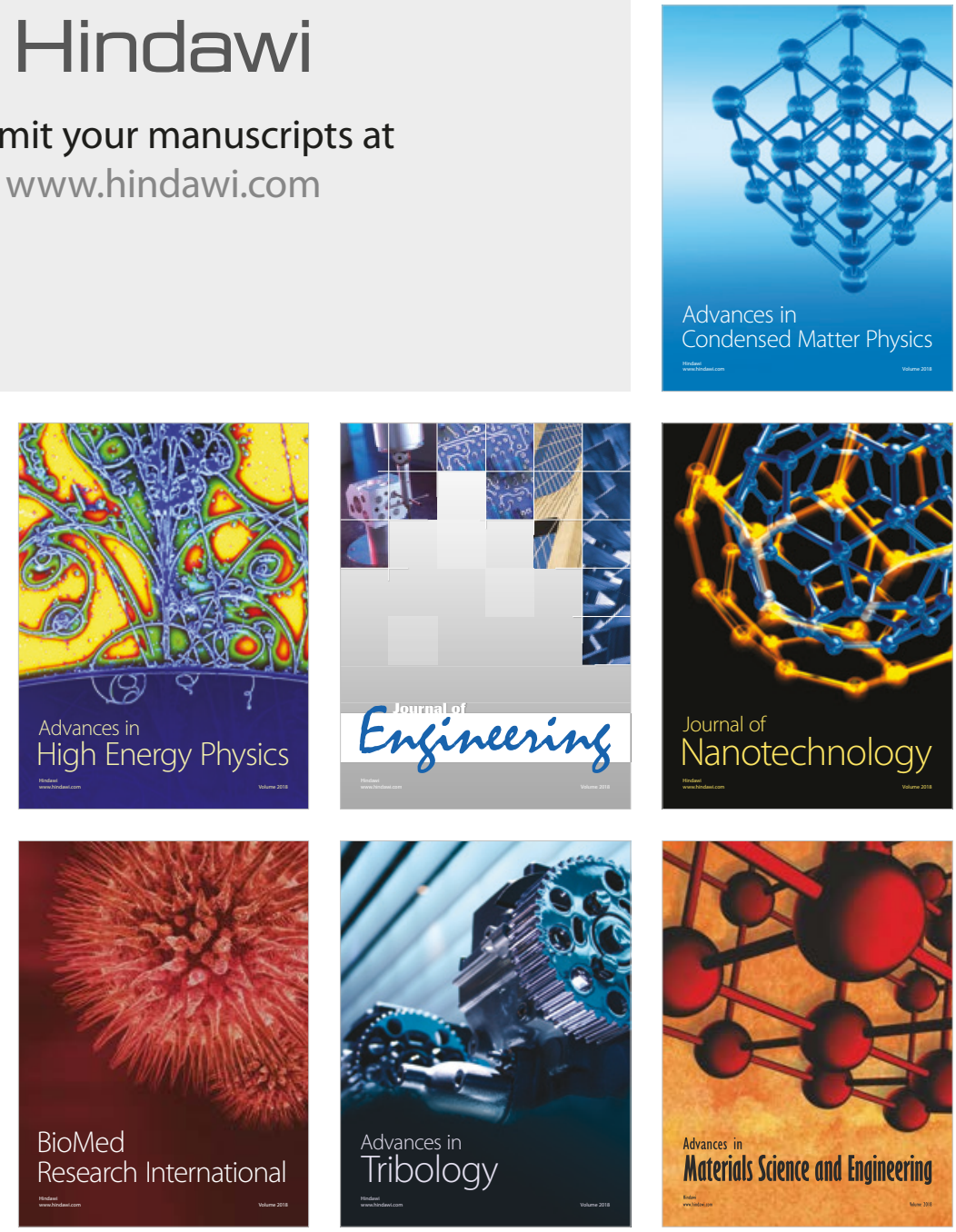